Article

\title{
"Because of the Christian Fellowship, I Decided to Stay": How Participating in a Christian Community Shapes the Social Experiences of Chinese International Students
}

\author{
Anke $\mathrm{Li}^{1}{ }^{1}$, Chi Nguyen ${ }^{1, *(1)}$ and Jinhee Choi ${ }^{2}$ \\ 1 Department of Education Policy Studies, The Pennsylvania State University, University Park, PA 16802, USA \\ 2 Department of Learning and Performance Systems, The Pennsylvania State University, \\ University Park, PA 16802, USA \\ * Correspondence: cpn110@psu.edu
}

Received: 29 June 2019; Accepted: 3 August 2019; Published: 7 August 2019

\begin{abstract}
This ethnographic study examines how participation in a Christian church community shapes Chinese international undergraduate students' social experiences in an American university. Our findings reveal that Chinese international undergraduate students identify the church and its fellowship as (1) a social support community and (2) an informal learning community, one which fills in the gap in counseling services and interpersonal activities that the university fails to offer. Recommendations are made for higher education institutions to provide stronger support for international students, regardless of their nationalities and religions.
\end{abstract}

Keywords: Chinese international students; Christianity; higher education; religious community

\section{Introduction}

Over the last few decades, the number of international students in the American higher education system has increased significantly. Students from Mainland China, in particular, have formed the largest international student group in the United States (32.5 percent of the international student body in the 2016-2017 academic year) and the number has continued growing (Institute of International Education (IIE) 2017). Together, Chinese international students have contributed to American higher education institutions academically, financially, and culturally (Chapdelaine and Alexitch 2004; Hanassab and Tidwell 2002). However, a wide range of literature on Chinese international students as a collective group has shown that they suffer from various challenges during their acculturation to the United States (e.g., Flannery and Wieman 1989; Hendrickson et al. 2011). Most of them have to deal with culture shock, language barriers, and academic challenges caused by unfamiliar teaching styles and learning environments (Agar 1996; Arasaratnam and Doerfel 2005; Hendrickson et al. 2011; Smith and Khawaja 2011; Spencer-Rogers and McGovern 2002; Williams and Johnson 2011).

Although most American higher education institutions acknowledge the struggles that international students face, they have not provided enough support for this student population (Austin et al. 1990; Khawaja and Stallman 2011). For example, many on-campus counseling centers lack culturally knowledgeable staff to cater their services to a diverse international student population (Hwang et al. 2014). Owing to cultural and language barriers, many Chinese international students are also reluctant to express their personal problems to American professors, peers, and counselors. Moreover, these students find it hard to share their issues with family members, who live far away and who cannot respond timely or effectively to their daily needs. As a result, students underutilized school counseling services and tended to rely on Chinese ethnic communities for emotional and mental 
support (Hanassab and Tidwell 2002). In order to better serve the growing number of international students, it is necessary that American universities understand how and where these international students seek support and how to provide them with better counselling and student affairs services.

While numerous studies address Chinese international students' social experiences in American universities, very few of them discuss these experiences in relation to religion, especially within the same ethnic group. Some studies mention the role of religious and spiritual beliefs on Chinese immigrants, but not on Chinese international students in particular (e.g., Cao 2005; Ng 2002). In the American higher education context, the relationship between higher education and Christianity as it pertains to Chinese international students is particularly intriguing. Before coming to the United States, many Chinese international students have little exposure to or experience with Christianity. In China, because religious practices are heavily controlled by the government, state-regulated churches have become the mainstream venues for Christian practices, while unregulated house churches and underground churches are often restricted (Yang 2009). Therefore, many Chinese international students are first introduced to unregulated Christian communities when they come to the United States. This unique context adds important nuances to the religious experiences of Chinese international students and to the formation of their religious-based support system.

Using an ethnographic approach, this study explores how participating in a Christian community shapes Chinese international students' social experiences in an American university in the Northeast. The article proceeds as follow: We first provide a review of the literature on Chinese international students' experiences in American higher education and with Christianity. Following a brief description of the theoretical frameworks, we discuss the study's research methodology and limitations. Then, we delve into our findings, which revolve around the students' descriptions of the church as (1) a social support community and (2) an informal learning community. The article concludes with a discussion of the research findings and recommendations for higher education institutions.

\section{Literature Review}

Globally, the number of students choosing to pursue higher education abroad has been increasing steadily. For decades, the United States has been one of the most common destinations for international students. According to the 2017 Open Doors Data, the number of international students at US colleges and universities increased by 3.4 percent in the 2016-2017 academic year-almost 35,000 more students than the previous academic year-raising the total number of international students to $1,078,822$ (IIE 2017). China has consistently sent the most students. In the 2016-2017 academic year, 32.5 percent (350,755 individuals) of the international student population in the United States was from China-a 6.8 percent increase from the previous academic year (IIE 2017). Since two-thirds of the international student population draw financial funds from sources outside of the United States, the American higher education and economy have benefited greatly from the consistent growth of international student enrollment (IIE 2017; Rhee and Sagaria 2004). According to the US Department of Commerce, international students contributed more than \$39 billion to the US economy in 2016, a large increase compared to the $\$ 35$ billion in the previous year (IIE 2017).

These Chinese young adults, after leaving their home country and migrating to the United States, face many struggles in the process of adaptation and acculturation. Even Chinese international students who perform well academically, still struggle socially, emotionally, and mentally (Sue and Zane 1985; Yang 2018). For decades, research studies have shown common problems facing Chinese international students in the United States, such as difficulty in making American friends, English incompetence, cultural differences, emotional distress, and social isolation (Ching et al. 2017; Culha 1974; Feng 1991; Henderson et al. 1993; Perkins 1977; Sun and Chen 1997; Yang 2018).

In addition, Chinese international students often deal with high levels of psychological and acculturative stress symptoms, including depression and anxiety. A study conducted by Cheung (2010) on 203 Chinese international students found that 47.5 percent of students reported depression symptoms and 48 percent reported anxiety symptoms. A similar study on 130 Chinese 
student participants at Yale University found that 45 percent of them reported symptoms of depression and 29 percent reported symptoms of anxiety (Han et al. 2013). Despite such a high level of mental health issues, Chinese students do not actively use the professional counseling services provided by their higher education institutions (Cheung 2010; Han et al. 2013). A study by Yan (2017) explained several factors that cause Chinese students' underuse of counseling services: lack of knowledge regarding counseling, doubts about the ability of a "stranger" to help, and stigma attached to counseling services. Instead of seeking help from professionals, international students are more likely turn to their fellow nationals for help with personal problems (Hanassab and Tidwell 2002; Swanbrow Becker et al. 2018). Many studies highlight that Asian students tend to be more reserved about expressing their personal problems and more likely to deny symptoms of depression (Futa et al. 2001, among others). In this sense, a community of people sharing Chinese languages, cultures, and values (i.e., a Chinese ethnic community) would play an important role in Chinese international students' adaptation processes.

Extensive studies on religion and immigration have shown that ethnic religious communities play an important role in the lives of recent immigrants, both as a venue of ethnic reproduction and as a force for assimilation and change (Dolan 1975; Yang 1999). For example, a study by Yang (1999) found that ethnic churches like Chinese Christian Church could help assimilate Chinese immigrants into American society via their conversion to Christianity, and it could also allow them to preserve traditional Chinese culture through the maintenance of certain linguistic, ritual, and symbolic practices. However, the influence of ethnic religious institutions on the lived experience of Chinese international students, who are not immigrants, in Christian churches has not received enough attention. In one of a very few studies addressing the spiritual life of Chinese students, Yang (2018) conducted a survey of 1008 Chinese students and scholars in the United States. The result showed that most of the respondents (92\%) had been proselytized by Protestant Christians. After coming to the United States, the number of Chinese students believing in Catholicism and Daoism doubled, while the number believing in Protestantism quadrupled, compared to the 2016 study (Yang 2018). This important study, however, did not delve deeply into the influence of religious participation in students' lived experiences.

While it is well known that many Chinese international students struggle during their processes of adaptation, it is unclear if and how being part of an ethnic religious community may help them adjust to socio-cultural and academic changes. Given the significant contributions of Chinese international students to American higher education institutions and the magnitude of their struggles during their time in the United States, it is important to understand how their participation in religious communities may shape their social experiences.

\section{Theoretical Framework}

The theory of social capital, developed by Robert Putnam, James Coleman, and Pierre Bourdieu has been widely borrowed to explain social relationships among people that enable productive outcomes (Brooks and Waters 2018). Studies by Coleman, in particular, address the relationship between religion and students' learning experiences-the central focus of this study. In his theoretical work, Coleman (1988) defines social capital as the aggregate value of social network-relations among people. Social capital is the product of investment strategies; in order to establish, develop, and reproduce social capital, people need to invest time, effort, and resources in social relationships. The closure of social networks can constitute useful capital resources for individuals in the form of trustworthiness, information channels, norms, and effective sanctions (Coleman 1988).

Coleman emphasizes the role of religious institutions in generating social capital among young people. For example, in a study that compared the dropout rates across Catholic, public, and private schools, he found a significantly lower dropout rate in Catholic schools (Coleman 1988). He explained that the "differences [in dropout rates] are not due to the religion of the students or to the degree of religious observance," since "Catholic students in public school are not slightly less likely to drop out than non-Catholics" (p. 114). He further added that the different dropout rates are strongly related to the "frequency of attendance at religious services, which is itself a measure of social capital 
through intergenerational closure" (p. 114). Coleman argued that the social capital that Catholic school students gain from their religious communities help them stay at school, which in turn, enriches their knowledge and skill sets (Coleman 1988).

However, such closure of social capital has also been criticized in both theoretical and empirical research. Granovetter (1973) "weak ties" theory, many scholars have discussed the negative effects of close networks (e.g., Aldridge et al. 2002; Tonkiss 2004). Studying the ties between the job changers and the contact people who provide the necessary information, Granovetter (1973) found that people who had a larger number of contacts who they did not know very well ("weak ties") were able to find more jobs than those people who had a smaller number of contacts who they knew better ("strong ties"). This is because "weak ties" allow people to access information that is different from what they may receive from their own network circle, as well as to extend their networks to new people (Granovetter 1973). Another negative consequence of "strong ties" is the pressures of conformity that close groups can place on their members, which in turn, limits individuals' freedom of actions and choices (Portes and Landolt 1996; Wall et al. 1998).

In this study, we borrow Coleman (1988) concept of social capital and Granovetter (1973) “weak ties" theory to form a theoretical framework within which to explore the relationship between Chinese international students' participation in ethnic Christian communities and their social experiences. Within this framework, students' religious participation can be thought of as a way of forming social capital and social ties among Chinese international students. These theories are particularly helpful because they allow us to explain both negative and positive influences of participating ethnic religious communities. Ultimately, they help us provide a more comprehensive and nuanced understanding of how church participation shapes the social experiences of Chinese international students.

\section{Methodology}

The study was guided by the following research question: How does participation in Christian fellowship shape Chinese international students' social experiences? To answer this question, we conducted a study on international student participants of a Chinese Christian church and fellowship located in an American college town in the Northeast. Given that the research question focused on individuals' subjective experiences and that the theoretical framework centered on social relations, we believed ethnography was the best methodological approach for this study. The study's ethnographic approach and its focus on a single research site allowed us to gain in-depth understandings of Chinese students' subjective experiences, beliefs, and perceptions during their participation in the Christian fellowship community and their connections to the students' lives outside of the community. In the following sections, we describe the study settings, our empirical approach, data collection, and data analysis.

\subsection{Settings}

This study focused on the social experiences of Chinese international undergraduate students who participated in a Chinese Christian community nearby campus. This community was centered around a local ethnic church, Chinese Home Church ${ }^{1}$, and its fellowship, Lighthouse Fellowship, that is geared towards undergraduate students. The college town where this community is situated is a small town in the Northeast; it is approximately 200 miles away from several major metropolitan cities. The center of this town is a large public research, land-grant university, which all student participants of this study attended. The community was selected as the study site because of its popularity among Chinese students and residents in this town. For over two decades, Chinese Home Church has been a prominent worship place for local Chinese Christians. Every Sunday, the church welcomes over 200 youth and adult Christians to come and worship in two languages: English and Mandarin Chinese. Among the seven fellowships of Chinese Home Church, Lighthouse Fellowship is the one that specifically caters to 
Chinese undergraduate students. The fellowship was created in 2008 as a response to the growing number of Chinese international undergraduate students on campus. Since 2011, the fellowship has held weekly Friday gatherings for students, which often start with a Chinese-themed dinner shared by all members and followed by Bible study hours in both big and small groups. The fellowship also holds annual events and celebrations, such as Halloween, Thanksgiving, Mid-Autumn Festival, Spring Festival, and events to welcome new students. During American holidays and academic breaks, when many domestic students leave the town to visit their families, Chinese international students often celebrate these holidays and spend their breaks with the community. By focusing on a single research site, we were able to immerse ourselves in the community for an extended period of fieldwork. Embracing our immersion, which involved "socialization into the rules, rituals, practices, beliefs, organizations, and daily life schedules of whose lives are the subject of study" (Schensul and LeCompte 2012, pp. 1-2), we developed a deep understanding of the community's distinctive context and culture.

\subsection{Empirical Approach}

Ethnography is best suited to examine and understand cultural patterns and behaviors of individuals or communities (Fetterman 2010). As Schensul and LeCompte claimed: “Ethnography takes the position that the best and most authentic way to understand a different cultural setting is to immerse oneself in it" (Schensul and LeCompte 2012, p. 1), ethnography provides ways of seeing, interpreting, and understanding peoples and cultures. In this study, ethnography allowed us to gain in-depth understandings of Chinese international undergraduate students' experiences, beliefs, and perceptions. It also enabled us to map our theoretical framework on to the relationship between students' participation in ethnic Christian communities-their social capital, strong/weak ties-and their experiences as Chinese international students in the United States. Chinese international students are often invisible in the predominantly US White education system (Hsieh et al. 2007) and are stereotyped as a homogenous group despite their diverse backgrounds (Grimshaw 2007). With this ethnographic approach, we gave voices to our participants and empowered them to share their everyday struggles and endeavors.

We (the researchers/authors) have substantial personal and professional experiences with international student populations, particularly Asian international students. The first author, a native Chinese speaker, has actively participated in this local Chinese Christian community for over two years. She began participant and non-participant observations and interviews for the study after one year of being in the community. The second and third authors are Vietnamese, non-Christian and Korean, Christian, respectively; both have been involved in different Asian ethnic Christian communities onand off-campus and were introduced to the community in the year that this study started. Drawing upon our close and trusted relationships with participants, we were able to engage with participants' constructions of beliefs and perceived realities. Because the church was based on the same ethnic group, the three researchers' Asian ethnic backgrounds allowed us to access this exclusive social world and to search for meanings embodied in this world which would otherwise go unnoticed. Moreover, the researchers' identities, both Christian and non-Christian, Chinese and non-Chinese, and in-between, also created frequent opportunities to constantly reflect on our emic (insider) and etic (outsider) perspectives. Such reflection allowed us to develop a multidimensional ethnographic approach (Geertz 1973). These commonalities and differences in our ethnic and religious backgrounds also helped us triangulate our perspectives and address our biases. For example, our shared East Asian background helped us immerge ourselves into the Chinese culture of the community and understand participants' thoughts and emotions as foreigners in the United States. Meanwhile, our diversity in sub-Asian groups (i.e., Chinese, Korean, and Vietnamese) and religious beliefs allowed us to constantly cross-check our cultural biases among ourselves and to interpret our data from different perspectives. Acknowledging the complexity of listening and learning across cultural difference, we made a conscious effort to articulate, question, and triangulate researchers' biases and data saturation (Bernard 2012; Chenail 2011). 


\subsection{Data Collection}

After obtaining approval from the Institutional Review Board (IRB) to study human subjects, we discussed our study with Chinese Home Church and Lighthouse Fellowship mentors and student leaders - the "gatekeepers" - and asked their permissions to access the research site. Upon receiving their permission, we began the data collection process, which included participant and non-participant observations and interviews.

Over the course of thirteen months (from August 2016 to September 2017), we spent approximately six hours per week observing the Chinese Home Church worship services and Lighthouse Fellowship Bible study hours, weekly dinners, and informal gatherings. We paid particular attention to students' interactions and conversations during weekly dinners, as these were often the times when students would talk about their everyday lives and their interpretation of Bible study lessons. In addition, we attended and took notes at special events in the church and the fellowship, such as baptisms, birthday parties, campus recruitments, and welcoming parties for new fellowship members.

Concurrently, we conducted two rounds of open-ended, semi-structured interviews. Using a purposeful, snowball sampling technique, we recruited study participants verbally and by handing written recruitment letters in person. Only people who provided consent to participate in this study were recruited. The informed consent form provided to all participants clearly stated that participation in the study was voluntary and that participants were free to decline to participate and may withdraw their consent or discontinue participation at any time without penalty. Our interview participants included 14 Chinese international undergraduate students participating in Lighthouse Fellowship, one of whom also served as a junior leader in the fellowship. To have a better understanding of the history and organization of the Church and its fellowship, we also interviewed the pastor's wife, who served as a mentor of Lighthouse Fellowship. Guided by the ethnographic approach, our intention was to gather in-depth interview data with a focused group of participants who could share their social and cultural experiences as well as their perspectives on the community.

During the first round of interviews, we asked Chinese undergraduate students to share their stories and experiences of participating in the church/fellowship and how these experiences have shaped their lives in the United States. These questions were designed to help the researchers understand participants' culture and lived experiences within and beyond the ethnic Christian community. After the initial coding of our first round of interviews, we started the second round of interviews. In this round, we conducted follow-up interviews with six previous student participants. With more tailored and in-depth questions, we asked participants to reflect on how the church and fellowship help them develop their social networks and social skills. We also asked their opinions about friendship inside and outside of the church. In addition, to better clarify the process of planning and socialization from the church perspective, we asked the church mentors and student leaders about the process of "recruiting" international students and their thoughts that inspired them to volunteer on the benefits of church participation to Chinese undergraduate students. Interviews were conducted in Chinese and then translated into English. (See Table 1).

\subsection{Data Analysis}

During and after the data collection process, we held weekly meetings to discuss strategies for data analysis and exchange interpretations of data. Because the interview data were in Chinese, the first author, a native speaker, transcribed and translated all the interviews. With all data translated into English, we collectively reviewed all field notes, memos from interviews, and interview transcripts to develop a comprehensive understanding of the data. We then applied open coding to all data sources, looking for themes that emerged from both observations and interviews. Major codes and corresponding excerpts were also created and sorted in this initial stage. Sequentially, with our research question and theoretical framework in mind, we coded data that spoke to the influence of church/fellowship participation and students' social experiences. After two rounds of coding, 
we compared all codes and excerpts gathered across data sources collectively to make sure all meaningful data were thoroughly and critically considered.

Table 1. Interview participants.

\begin{tabular}{|c|c|c|c|c|c|c|c|c|}
\hline Pseudonym & Sex & Age & Major & $\begin{array}{l}\text { Year in } \\
\text { College }\end{array}$ & Baptism & $\begin{array}{c}\text { First } \\
\text { Generation } \\
\text { Christian }\end{array}$ & $\begin{array}{c}\text { Initial } \\
\text { Interview } \\
\text { Date }\end{array}$ & $\begin{array}{l}\text { Interview } \\
\text { Language }\end{array}$ \\
\hline Linshu & $\mathrm{F}$ & 19 & Psychology & 2 & Yes & Yes & $16 / 11 / 2016$ & Chinese \\
\hline BaiXi & $\mathrm{F}$ & 20 & Economics & 2 & Yes & Yes & $22 / 2 / 2017$ & Chinese \\
\hline Xiaoshu & $\mathrm{F}$ & 21 & Earth Science & 2 & Yes & No & $22 / 2 / 2017$ & Chinese \\
\hline Luo & $\mathrm{F}$ & 22 & Communication & 4 & Yes & No & $26 / 3 / 2017$ & Chinese \\
\hline Feiyang & M & 21 & Information Cyber Security & 3 & Yes & Yes & $7 / 4 / 2017$ & Chinese \\
\hline Jing & $\mathrm{F}$ & 19 & Math Actuarial Science & 1 & Yes & Yes & $27 / 4 / 2017$ & Chinese \\
\hline Jie & $\mathrm{F}$ & 22 & Supply Chain Management & 4 & Yes & No & $17 / 5 / 2017$ & Chinese \\
\hline Xian & M & 22 & Environmental Engineering & 3 & No & Yes & $8 / 8 / 2017$ & Chinese \\
\hline Xiangke & $\mathrm{F}$ & 22 & Sociology & 3 & Yes & Yes & $8 / 8 / 2017$ & Chinese \\
\hline Kou & M & 24 & $\begin{array}{l}\text { Comparative Education; } \\
\text { Hospitality Management }\end{array}$ & 6 & Yes & No & $15 / 8 / 2017$ & Chinese \\
\hline Siwen & M & 23 & Computer Science & 5 & Yes & No & $10 / 8 / 2017$ & Chinese \\
\hline Hui & $\mathrm{F}$ & 22 & Hospitality Management & 3 & Yes & Yes & $13 / 9 / 2017$ & Chinese \\
\hline Yue & $\mathrm{F}$ & 22 & Hospitality Management & 3 & No & No & $13 / 9 / 2017$ & Chinese \\
\hline $\begin{array}{l}\text { Chenjing } \\
\text { (mentor) }\end{array}$ & $\mathrm{F}$ & $\sim 50$ & - & - & Yes & Yes & $12 / 4 / 2017$ & Chinese \\
\hline
\end{tabular}

Coded data were then analyzed using the thematic approach (Boyatzis 1998). Themes, as described by Boyatzis, are "[patterns] found in the information that at minimum describes and organizes the possible observations and at maximum interprets aspects of the phenomenon ..., [which] maybe initially generated inductively from the raw information or generated deductively from theory and prior research" (Boyatzis 1998, p. 4). In this study, thematic analysis allowed us to see prominent themes that emerged from the data, organize them systematically, and make interpretations of excerpts in their contexts and according to the theoretical framework. Some major themes identified during this stage includes changes after church/fellowship participation, the church as a social support community, the church as an informal learning/academic support community, the church community is just as important if not more important than family, and conflict with parents in Mainland China because of church/fellowship participation. These themes later became the backbone of this paper, upon which we developed the findings section below.

\subsection{Limitations}

We acknowledge three limitations to this study. First, the outcomes of students' participation in the church and its fellowship were self-reported. By focusing on the subjective experiences of Chinese Christian international undergraduate students, we did not obtain objective measures of students' social performances that might show changes before and after their church participation. Future research that obtains objective data across different settings over an extended time would address this limitation.

Second, while our study offers implications for Chinese international students, we did not trace their development in comparison to non-church participants. Thus, we were unable to specify the role of the church and its fellowship in Chinese students' development that were separate from other factors shaping their lives abroad. This limitation will be addressed in our forthcoming study, which compares the experiences of Chinese international undergraduate students who participate in the Christian community and those who do not.

Third, the Chinese Christian community depicted in this study was situated within the context of a small college town surrounded by a major public university where all student participants attended. It may be that this particular context was a factor that shaped Chinese international students' spiritual/religious and social experiences. These experiences can be different in other contexts, such as in a more diverse urban area where there is a larger Chinese population or in a faith-based private university where religious participation is more common among students. While our study is resonant 
with research findings on similar topics in other communities and institutions (e.g., Sharma and Guest 2013; Yang 2018), the particular context of this study may limit the applicability of our findings to communities and institutions with similar sizes, demographics, and religious dynamics.

\section{The Church as a Social Support Community}

\subsection{A Welcoming and Caring Community}

From both our observations and interviews, it is clear that the Chinese Home Church and its Lighthouse Fellowship successfully provided an overall welcoming and caring environment for Chinese international students. This positive environment meant a great deal for the students, particularly those who recently arrived in the United States and began adjusting to American culture and its higher education system. Most of our participants viewed the church and its fellowship not only as a place to exercise their religious practices but also a second home that strengthened their sense of belonging and social relations. This was especially true for those participants who had previously experienced Christian fellowship in American high schools. For them, people from any church were generally trustworthy. Linshu, a 19 year old female student who had attended a Christian high school, recalled her first day in town:

"I still remember my feeling after arriving at [the local] airport, I felt lost and unfamiliar. Everything was new to me. I thought that no one would pick me up at the airport. I didn't know how to take a bus or a taxi to my dorm. Suddenly, I saw Jiahe, ... Our student leader, Jiahe. He stood right beside the exit door and held a flag that read: "Chinese Home Church welcomes new students." I still remember my feeling at that moment. I knew that I was home. I didn't feel lost anymore. I had a sense of belonging here." (Interview, 16 November 2016, in Chinese)

Although the university officially welcomes new international students in annual orientations, these sessions often focus on codes of conducts and academic requirements, rather than interpersonal support. The church and its fellowship take a step further by welcoming international students individually and helping them get settled when they arrive. This approach makes these students feel more welcomed, safe, and supported. More importantly, the welcoming name of the Christian church and fellowship makes students feel secure. Like Linshu said, "I knew I was home." Even though she had just met Jiahe for the first time, she trusted him and felt a sense of belonging.

For those students who were not familiar with Christian churches and fellowships, the Church and its fellowship organized recruitment activities and welcoming activities for new students during the annual orientation. Their welcoming approach was not about proselytizing. Instead, it was an expression of care for the feelings and experiences of new students. For example, the Church and its fellowship thought new students would be lonely and homesick, so they prepared and served traditional Chinese food for new students. In talking about this caring approach, most of our participants shared that the early connection they had with the church and its fellowship offered them a sense of belonging that they would not have had otherwise.

In addition, throughout the school year, the Church and its fellowship routinely organize activities and events with their members. Chief among them are group birthday celebrations, organized weekly or bi-weekly by fellowship leaders and students in charge. They prepare homemade birthday cakes, candles, gifts, and social opportunities within one or two weeks of all students' birthdays. These types of interpersonal activities have shaped a family-like community environment within the church, making students feel a sense of support and belonging. Linshu shared:

"I think now the church is more important than family. I don't mean that family is not important. But my parents are too far away; they are unable to guide me effectively. Meanwhile, in our church community, the leaders are like my parents and they take good care of me. Brothers and sisters in the church community are all friendly and willing to help 
me. They could help me in time when I am in trouble. Like several weeks ago, I encountered a financial issue and it really bothered me. I did not tell my parents because they are too far away and even if they knew, they could not help me right away. Telling them not only wouldn't solve the problem but also make them feel worried. So, I told my friends and the student leaders in the church; they gave me many suggestions to solve the problem. They've always supported me every time I was in trouble." (Interview, 16 November 2016, in Chinese)

The church community is just as important if not more important than family is a common theme that we found across our interviews. For Chinese undergraduate students, most of whom grew up in the Chinese one-child policy era, this is their first time living away from their parents. They soon realize that their parents are no longer able to respond to their needs timely and effectively. Therefore, our participants often rely on the church community in times of difficulty. The church's pastor and senior mentors, whose cumulative knowledge and experience in the ministry well equips them for this role, become parental figures to Chinese undergraduate students and offer them trustworthy judgments and advice.

The community also welcomes students who are new to Christianity or to the church/fellowship to join all activities as regular members. To ensure everyone is able to recognize new members, the fellowship student leaders often kick off an event with an introduction. We recorded one such introduction in the beginning of a Bible study hour:

In the big group meeting, after singing contemporary worship songs, the band found chairs to sit down on. Then, a female student leader, Jiajia, took the microphone and started the general weekly report. She first asked if there were any newcomers at today's meeting. A girl stood up and introduced herself and her major. Jiajia asked other students to say hello and welcomed the newcomer with hugs. Then, Jiajia asked everyone to say "It is nice to see you here today" to people sitting nearby. Everyone responded and hugged each other. (Field notes, 21 October 2016)

Given the regulated rules of Christian practices in Mainland China, many Chinese international students coming to the church/fellowship have little prior experience of and knowledge about Christianity. Yet, the Church did not only focus on introducing Christianity or on Church activities. For them, the first thing was to introduce newcomers and to welcome them with hugs. Such welcoming rituals may help newcomers feel less intimidated. They define the church as a community of hospitality, rather than as a place of rigid rituals and regulations.

\subsection{A Social, Emotional, and Mental Support Community}

When asked about our participants' social life, most students said that the majority if not all of their friends were from the church and the fellowship. From their perspectives, church/fellowship friends were "different" from friends who they made outside of the Christian community. Some students even said that: "Friendships out of church are not real." Emphasizing the important role of "friends in church", Xiangke, a female senior student, shared:

"Church friends are the primary sources for help. We usually turn to friends in church for help when facing problems ... Church, especially the fellowship, is like a family, and people in church or fellowship are family members, you don't need to feel intimidated to express yourself and your concerns. Friends in the church are different, I mean, you can tell them everything, since they tell you everything." (Interview, 8 August 2017, in Chinese)

Echoing Xiangke, most participants expressed strong comfort and trust when interacting with other church/fellowship members. They considered this community to be a safe place that provides social and mental support during their lonely and insecure time abroad. For example, opening up about her experience with depression, Xiaoshu said: 
"If I had not made any contact with the fellowship at the beginning, I would have had nothing. With my personality, I don't take the initiative to meet others. I think I would be alone for a long time. Like, becoming very depressed ... I wasn't able to make friends in high school [and during that time,] I felt very dark. [But] my mother said that after entering college, I would be happier. [Indeed,] I have really been cheered up a lot because I met many good friends in the fellowship." (Interview, 22 February 2017, in Chinese)

In Xiaoshu's view, her loneliness and depression have been transformed into happiness after joining the Lighthouse Fellowship. She stressed multiple times in conversations with us that her participation in the fellowship has radically changed her mental wellbeing, mainly because she "met many good friends in the fellowship".

From the organizer's perspective, Chengjing, a mentor of Lighthouse Fellowship, always emphasizes the role of the fellowship in creating a community for students to develop social connections and emotional support systems. She stated:

"In terms of emotional needs, we need friends, we need to have good friends, we need to be able to communicate, need to have our own companions to make decisions and do things together. It is very important to build a healthy environment here where we could provide the students what they need when they need us, based on Christian belief and practice." (Interview, 12 April 2017, in Chinese)

The communal activities within the church/fellowship, therefore, are not arbitrary. Rather, they are carefully planned and grounded within Christian ethics of community.

Respectively, many students shared with us that they perceived the church and its fellowship as a counseling-like community where they can come for advice on emotional distress and mental illness. For example, Baixi shared:

“Last year, my roommate and I had many disputes ... I felt helpless. I felt desperate. [Then,] it was Xiushan Sister [a Lighthouse Fellowship mentor]. She took me to pray, go to Bible study, and to help me reconcile the disputes. Afterwards, my mood and perspective were transformed; the situation became much better."

(Interview, 22 February 2017, in Chinese)

While the university does provide professional counseling services, our participants often turned to the church and the fellowship for mental support. Being able to express themselves in their own language and cultural norms, they found it easier to share their thoughts and feelings with Chinese Christian community members than with American counselors. Many students also said that they often felt "relieved" and "relaxed" when they go to church. They credited the church community for providing a safe place where students can support each other mentally and emotionally. This ethnic Christian community, therefore, fills the gap in counseling services that the university has not yet successfully adapted to international Chinese students.

\section{The Church as an Informal Learning Community}

\subsection{A Learning Community of Information Exchanges}

Throughout the school year, we observed numerous occasions in which students exchanged academic information and knowledge with one another during church/fellowship activities. Most students mentioned that they used their church networks as resources to find academic advice for their advancements. For example, we recorded an exchange around a dining table:

Around the dining table, there were seven female students and me [the first author]. Most of the conversations were about academic issues, such as majors, assignments, and examinations. Mengmeng was new to this weekly church activity. When Mengmeng said that her major is 
Art History and Communication Art \& Science (CAS), the other girls reacted immediately. One girl asked what CAS major was and Mengmeng gave detailed explanations to her. Then, another girl Yanyan asked whether Mengmeng could help her choose a picture for her assignment. Other girls overheard this request, and they all provided their opinions about the selection of pictures. One girl suggested Yanyan should choose a Chinese famous picture: "There are many characters in this picture, and there must be a lot of information you could describe and comment." Mengmeng agreed with this girl. Yet, another girl gave a different opinion. She stated, "This picture is too well-known, and there must be many students choosing this picture for assignments." Mengmeng also agreed. Together, they helped Yanyan decide on using the well-known Chinese picture for the assignment. (Field notes, 21 October 2016)

In this particular observation, it was clear that although Mengmeng was new to this church community, she was immediately connected to other members by exchanging academic information. Also, by talking to Mengmeng, other student members expanded social connections and obtained knowledge beyond their own majors. More importantly, Yanyan was able to use this opportunity to receive helpful feedback about her assignment.

This type of academic exchange occurred frequently in the mentor-like relationship between new and recurring students. Because, all undergraduates in this university are required to take similar mandatory courses, senior students in the community often mentored junior students as they made academic decisions about courses, textbooks, and advisors that would benefit junior students' studies. In conversations with us, many participants mentioned that this shared knowledge is crucial for navigating their academic journeys in the United States. Moreover, since students build sound relationships with each other, they can ask for academic help directly. For example, Xiaoshu said,

"Kim [a Lighthouse Fellowship member] is a straight A student. So, if I have something I really don't know, I can just ask her." (Interview, 22 February 2017, in Chinese)

Such interactions reveal how informal learning takes place outside of class. Through social connections and communal supports, students can gain important knowledge and information, which they use to improve their academic performance. This pattern was highlighted in James Coleman (1988) argument that social capital can be transformed into other types of capital, such as human capital. Thus, by participating in church activities, Chinese international students strengthen their social capital, which in turn can benefit their academic experiences.

\subsection{An Informal Academic Support with Learning Motivation}

Interactions among international students were not limited to weekly church activities; it extended to students' daily lives. For example, Linshu stated:

"I met many good people in the church and I made close friends with some of them. We actually have many interactions during the weekdays, not just in church weekend activities. We study and hang out together. You know, when you study alone, you may feel lonely. But if you study with someone else, even you two are not studying the same subject, you still feel more encouraged and energetic. Being accompanied feels much better." (Interview, 16 November 2016, in Chinese)

Echoing Linshu, many participants shared that most of the time, they do not demand direct academic support from their peers, rather, what they long for is company. This is precisely what the Chinese Christian community has provided to their members. It offers them a place to meet regularly and reminds them that whatever happens, their church peers and mentors-their sources of support-will always be there.

More importantly, fellowship members often inspire one another to engage with school work seriously. Even when students are not in the same major, they are still willing to study together in 
the library. Such study groups help motivate students to focus on their assignments and to work hard to achieve their academic goals. Our participants mentioned that their communal study groups inspire them to ponder upon the purposes of life, the meanings of their academic journeys, and their own futures. This pattern shows how social capital can be transformed into human capital within the context of religious community.

\subsection{Drawbacks of Participating in the Church}

Despite various benefits that Chinese international undergraduate students have gained from participating in communal activities, there are several drawbacks. First, while the church and fellowship activities help enrich students' lives, they also limit the students' flexibility in social planning. Thinking about the Bible study section that she attends every Friday, Baixi said:

"[It has] both positive and negative sides. The positive side is that I get to meet so many friends. However, because the church activities have fixed times, I have to schedule everything around those times [and prioritize them over other things]." (Interview, 22 February 2017, in Chinese)

Having "fixed times" and inflexible schedules at the church/fellowship, many participants put off other social opportunities both inside and outside of campus. As a consequence, most of their social interactions only occur within this Chinese Christian community.

Second, the students' involvement in religious activities has become a concern of many parents, who expect their children to focus on their studies, rather than on religion. To one of our participants, Feiyang, this has been a long-standing tension. He shared:

"[My parents] always tell me that I am spending too much time in the church and the fellowship. [ ... ] I myself don't feel this way. But not only my parents, other people also asked me: 'Do you want to be a missionary? Do you want to be a preacher? Do you want to be a pastor?' I said: 'No.' Then they said: 'You have spent so much time on this, do you think it's worth?'" (Interview, 7 April 2017, in Chinese)

Similar to Feiyang, many participants admitted that because their parents have spent a great amount of money to send them abroad, they are expected to devote their time and effort to academic training. Time spent on religious activities is often considered as time taken away from studying, working, and job hunting. This has been a great concern of many participants' parents in China.

Because the church and fellowship activities often demand a huge amount of time and attention, it is difficult for students to find a balance between lives inside and outside of the church. This may affect students' study time and limit their social circles. In addition, it can lead to lower levels of exposure to American culture, language, and society-important aspects of their experiences abroad.

\section{Discussion and Conclusions}

Our findings show that the church and its fellowship have strong influences on Chinese international undergraduate students. These influences have both positive and negative effects. Positively, the church and its fellowship provide students with a stable social and informal learning community, which help students build strong social bonds with each other. Such connections reproduce sustainable social capital among the students (Coleman 1988), helping them to enrich their lives socially and, to some extent, academically. In terms of social support, the church and its fellowship serve as welcoming and caring places for Chinese undergraduate students when they are thousands of miles away from their families. They function together as a student organization, providing a variety of activities to help students connect with one another and to expand their social networks based on faith and trust. They also function as an informal counseling center, where students can share their emotional and mental distress and receive practical and culturally relevant advice. In terms of informal learning and academic support, church/fellowship members often exchange knowledge and motivate 
one another to study. Collectively, our participants claimed that they were well informed and more motivated to study thanks to their church/fellowship participation.

While the university does provide international students social, academic, and mental support outlets, our participants still preferred the informal and relational support from the church/fellowship. This preference may be due to the cultural and linguistic barriers between Chinese international students and American service providers, particularly school counselors and service providers. Additionally, as suggested by our study's participants, almost none of the existing non-religious organizations could provide the same level of spiritual connection, collective support, and family-like atmosphere as the church does. This is consistent with Sharma and Guest (2013) study on Christian students' experiences in English universities. They found that by providing a context for students to make new friends or lifelong partnerships, church communities may act as a "surrogate family" and facilitate connections between and among individuals (Sharma and Guest 2013). Similarly, Li (2012) examined the impact of wider social contact on the experiences of Chinese postgraduate students adapting to the life in the United Kingdom. This study revealed that Chinese students' frequent social contact with a local volunteer group, whose participants were mostly Christian, helped fill in their support needs that were not adequately met by the university ( $\mathrm{Li} 2012$ ). Given the high levels of acculturative stress among Chinese international students and their underutilization of university mental health services (Cheung 2010; Han et al. 2013), it is important to recognize that religious communities-such as the one mentioned in this study-are filling the gap in services that higher education institutions fail to provide for their international students.

Despite these major benefits, participation in the church/fellowship had negative effects on students. In order to develop such strong relations in this community, most participants spend a significant amount of time in Friday gatherings and at Sunday worship events. This investment may take the time away from their studies. More importantly, it can restrict students' social interactions to people and activities within the church/fellowship. This limitation would likely reduce students' opportunities to widen their social connections and gain "weak ties" outside the church and fellowship. In this sense, students may circulate similar information since they share the same information sources, and are less likely to gain different resources outside of and perspectives beyond their church community (Granovetter 1973). Moreover, this limitation reduces students' chances to explore diverse cultural and social experiences in the United States, which is an important aspect of studying abroad.

This study contributes to the literature on the relationship between religious participation and students' experiences. Our findings reveal that this Chinese Christian community puts effort in to cultivating a support system with a caring culture that helps Chinese international undergraduate students socially and academically. Church activities, in this regard, are carefully and purposefully designed to nurture students' relationships. They also enable the students to practice their biblical values of love and kindness, an opportunity which is arguably a unique benefit that the church community brings to international students compared to other communities. Accordingly, the expansion of social capital is attributed to such intentional relationship building and religious dedications.

The study may also help scholars understand Chinese international undergraduate students' learning outside of formal educational settings. After over a year of participant observations and interviews, we found that our participants valued their relational and communal engagements from this ethnic Christian community. Their social bond allowed them to sustain and pursue their social and academic goals. Our study, therefore, unpacks layers of communal support from a religious-based organization, a setting which is scarcely discussed in the context of Chinese international students' experiences in American higher education. The study calls for more attention from educational stakeholders to enhance the lived experiences of international students through religious, community-based, and other informal outlets. 


\section{Recommendations for Higher Education Institutions}

Based on the study's findings, we provide the following suggestions for higher education institutions, especially their counseling services and student affairs departments, to better support Chinese international students:

First, higher education institutions need to understand the everyday struggles that Chinese international students face during their process of adaptation and to use this knowledge to design corresponding counseling services. Our study shows that Chinese undergraduate students need more practical help and guidance in their daily life. Our participants preferred sharing their academic, social, and personal issues with the Chinese Christian community members because the church/fellowship can provide more timely, practical, and friendly support in linguistic and cultural terms that they can understand. Learning from the strength of such religious community, higher education institutions should enhance their counseling services. The counseling offices should provide counseling services in languages besides English that the majority of their international student body are familiar with. The counseling offices should hire counselors that have international and/or multicultural personal and professional backgrounds, who may have more in common with international students. That way, international students will feel more welcome in the on-campus counseling services and higher education institutions will have the opportunity to learn more about international students.

Second, by acknowledging the negative influence of church and fellowship on students, student affairs departments can work to help students supplement their core social network with other vital "weak ties." Higher education institutions can organize activities and collaborations among various fellowships and associations across races, ethnicities, cultures, and nations (Park and Kim 2013). In that way, international students will have more opportunities to meet new people outside of their ethnic communities. These efforts can also help expand diversity on and off campus.

Third, save for the small number of international students participating in ethnic-religious communities, most international students do not have access to such family-like communities. Therefore, it is important for higher education institutions to learn from this community model. Specifically, the counseling services departments and student affairs departments could use this model to create other welcoming, caring, and supportive communities or organizations for their international students. Although there are some commonalities between domestic and international students in terms of adaptation to college life, such as linear and progressive adjustment patterns (Hechanova-Alampay et al. 2002), uncertainty, anxiety, and financial concerns (Fritz et al. 2008; Sharma and Guest 2013), Chinese international students have distinctive sociocultural needs and preferences from domestic students and from international students of non-Chinese or non-Asian origins (Zhao et al. 2005). This complexity makes it difficult for higher education institutions to provide services to meet all needs. However, if the campus services can provide a form of community support, community members can organically help one another without direct institutional supervisions. Therefore, the counselling services and student affairs need to cooperate to create focused community organizations on campus that are open to all international students (religious or not), in order to provide a sense of belonging. These departments could also provide mentors in these focused community organizations to international students. Moreover, higher education institutions need to support students to organically create their own organizations on or off campus and to provide guidelines to make these organizations benefit from the Christian community model.

Author Contributions: A.L., C.N. and J.C. conceived and designed the research; A.L. led the data collection process; A.L., C.N. and J.C. analyzed the data and wrote the paper.

Funding: This research received no external funding.

Conflicts of Interest: The authors declare no conflict of interest. 


\section{References}

Agar, Michael H. 1996. The Professional Stranger: An Informal Introduction to Ethnography. London: Academic Press. Aldridge, Stephen, David Halpern, and Sarah Fitzpatrick. 2002. Social Capital: A Discussion Paper. London: Performance and Innovation.

Arasaratnam, Lily A., and Marya L. Doerfel. 2005. Intercultural communication competence: Identifying key components from multicultural perspectives. International Journal of Intercultural Relations 29: 137-63. [CrossRef]

Austin, N. Lavada, Robert T. Carter, and Alan Vaux. 1990. The role of racial identity in Black students' attitudes toward counseling and counseling centers. J. Coll. Stud. Dev. 31: 237-44.

Bernard, Russell H. 2012. Social Research Methods: Qualitative and Quantitative Approaches, 2nd ed. Thousand Oaks: Sage.

Brooks, Rachel, and Johanna Waters. 2018. Signalling the 'multi-local' university? The place of the city in the growth of London-based satellite campuses, and the implications for social stratification. Social Sciences 7: 195. [CrossRef]

Boyatzis, Richard E. 1998. Transforming Qualitative Information: Thematic Analysis and Code Development. Thousand Oak: Sage.

Cao, Nanlai. 2005. The church as a surrogate family for working class immigrant Chinese youth: An ethnography of segmented assimilation. Sociology of Religion 66: 183-200. [CrossRef]

Chapdelaine, Raquel Faria, and Louise R. Alexitch. 2004. Social skills difficulty: Model of culture shock for international graduate students. Journal of College Student Development 45: 167-84. [CrossRef]

Chenail, Ronald J. 2011. Interviewing the investigator: Strategies for addressing instrumentation and researcher bias concerns in qualitative research. The Qualitative Report 16: 255-62. Available online: www.nova.edu/ssss/QR/ (accessed on 25 June 2108).

Cheung, Poi Ten Ada. 2010. Depressive Symptoms and Help-Seeking Preferences among Chinese (including Mainland China, Hong Kong, and Taiwan) International Students. Houston, TX: University of Houston.

Ching, Yuerong, Susan L. Renes, Samantha Mcmurrow, Joni Simpson, and Anthony T. Strange. 2017. Challenges facing Chinese International students studying in the United States. Academic Journals 12: 473-82.

Coleman, James S. 1988. Social capital in the creation of human capital. American Journal of Sociology 94: 95-120. [CrossRef]

Culha, Meral Ulker. 1974. Needs and Satisfactions of Foreign Students at the University of Minnesota. Ph.D. Dissertation, University of Minnesota, Minneapolis, MN, USA.

Dolan, Jay. 1975. The Immigrant Church: New York's Irish and German Catholics. Baltimore: John Hopkins University.

Feng, Jianhua. 1991. The Adaptation of Students from the People's Republic of China to an American Academic Culture. In ERIC Document Reproduction Service ED 329833. Memphis: Memphis State University.

Fetterman, David M. 2010. Ethnography: Step by Step, 3rd ed. Thousand Oaks: Sage.

Flannery, Raymond B., and Dow Wieman. 1989. Social support, life stress, and psychological distress: An empirical assessment. Journal of Clinical Psychology 45: 867-72. [CrossRef]

Fritz, Marie Väfors, Dorothy Chin, and Valerie DeMarinis. 2008. Stressors, anxiety, acculturation and adjustment among international and North American students. International Journal of Intercultural Relations 32: 244-59. [CrossRef]

Futa, Kristine, Toshiko, Eugenia Hsu, and David J. Hansen. 2001. Child sexual abuse in Asian American families: An examination of cultural factors that influence prevalence, identification, and treatment. Clinical Psychology: Science and Practice 8: 189-209. [CrossRef]

Geertz, Clifford. 1973. The Interpretation of Cultures: Selected Essays. New York: Basic Books.

Granovetter, Mark S. 1973. The strength of weak ties. American Journal of Sociology 78: 1360-80. [CrossRef]

Grimshaw, Trevor. 2007. Problematizing the construct of 'the Chinese learner': Insights from ethnographic research. Educational Studies 33: 299-311. [CrossRef]

Hanassab, Shideh, and Romeria Tidwell. 2002. International Students in Higher Education: Identification of Needs and Implications for Policy and Practice. Journal of Studies in International Education 6: 305-22. [CrossRef]

Han, Xuesong, Xuemei Han, Qianlai Luo, Selby Jacobs, and Michel Jean-Baptiste. 2013. Report of a mental health survey among Chinese international students at Yale University. Journal of American College Health 61: 1-8. [CrossRef] [PubMed] 
Hechanova-Alampay, Regina, Terry A. Beehr, Neil D. Christiansen, and Roger K. Van Horn. 2002. Adjustment and strain among domestic and international student sojourners: A longitudinal study. School Psychology International 23: 458-74. [CrossRef]

Henderson, George, Virginia Milhouse, and Ling Cao. 1993. Crossing the gap: An analysis of Chinese students' culture shock in an American university. College Student Journal 27: 380-89.

Hendrickson, Blake, Devan Rosen, and R. Kelly Aune. 2011. An analysis of friendship networks, social connectedness, homesickness, and satisfaction levels of international students. International Journal of Intercultural Relations 35: 281-95. [CrossRef]

Hsieh, Peggy, Jeremy R. Sullivan, and Norma S. Guerra. 2007. A closer look at college students: Self-efficacy and goal orientation. Journal of Advanced Academics 18: 454-76. [CrossRef]

Hwang, Bong James, Robert Bennett, and James Beauchemin. 2014. International students' utilization of counseling services. College Student Journal 48: 347-55.

Institute of International Education (IIE) 2017. Open doors data. Available online: https://www.iie.org/Why-IIE/ Announcements/2017-11-13-Open-Doors-2017-Executive-Summary (accessed on 15 December 2018).

Khawaja, Nigar G., and Helen M. Stallman. 2011. Understanding the coping strategies of international students: A qualitative approach. Journal of Psychologists and Counsellors in Schools 21: 203-24. [CrossRef]

Li, Daguo. 2012. Out of the ivory tower: the impact of wider social contact on the values, religious beliefs and identities of Chinese postgraduate students in the UK. Race Ethnicity and Education 15: 241-58. [CrossRef]

$\mathrm{Ng}$, Kwai Hang. 2002. Seeking the Christian tutelage: Agency and culture in Chinese immigrants' conversion to Christianity. Sociology of Religion 63: 195-214. [CrossRef]

Perkins, Carolyn S. 1977. A comparison of the adjustment problems of three international student groups. Journal of College Student Personnel 18: 382-88.

Park, Julie J., and Young K. Kim. 2013. Interracial friendship and structural diversity: Trends for Greek, religious, and ethnic student organizations. The Review of Higher Education 37: 1-24. [CrossRef]

Portes, Alejandro, and Patricia Landolt. 1996. The Downside of Social Capital. Cambridge: New Prospect.

Rhee, Jeong Eun, and Mary Ann Danowitz Sagaria. 2004. International students: Constructions of imperialism in the Chronicle of Higher Education. The Review of Higher Education 28: 77-96. [CrossRef]

Schensul, Jean J., and Margaret Diane LeCompte. 2012. Essential Ethnographic Methods: A Mixed Methods Approach. Lanham, MD: AltaMira Press.

Sharma, Sonya, and Mathew Guest. 2013. Navigating religion between university and home: Christian students' experiences in English universities. Social \& Cultural Geography 14: 59-79.

Smith, Rachel A., and Nigar G. Khawaja. 2011. A review of the acculturation experiences of international students. International Journal of Intercultural Relations 35: 699-713. [CrossRef]

Spencer-Rogers, Julie, and Timothy McGovern. 2002. Attitudes towards the culturally different: the role of intercultural communication barriers, affective responses, consensual stereotypes and perceived threat. International Journal of Intercultural Relations 26: 609-31. [CrossRef]

Sue, Stanley, and Nolan W. Zane. 1985. Academic achievement and socioemotional adjustment among Chinese university students. Journal of Counseling Psychology 32: 570.

Sun, Wei, and Guo-Ming Chen. 1997. Dimensions of difficulties mainland Chinese students encounter in the United States. In ERIC Document Reproduction Service No. ED408635. Available online: https://digitalcommons.uri.edu/cgi/viewcontent.cgi?referer=https:/www.google.com/\&httpsredir= 1\&article $=1017 \&$ context $=$ com_facpubs (accessed on 5 August 2019).

Swanbrow Becker, Martin Shengli Dong, Julia Kronholz, and Chris Brownson. 2018. Relationships Between Stress and Psychosocial Factors with Sources of Help-Seeking Among International Students. Journal of International Students 8: 1636-61. Available online: http://ojed.org/index.php/jis/article/view/222 (accessed on 15 January 2019). [CrossRef]

Tonkiss, Fran. 2004. Trust and Social Capital. In Politics, Trust and Networks: Social Capital in Critical Perspective. Edited by J. Franklin. London: London South Bank University, pp. 17-22.

Wall, Ellen, Gabriele Ferrazzi, and Frans Schryer. 1998. Getting the goods on social capital. Rural Sociology 63: 300-22. [CrossRef]

Williams, Christina. T., and Laura R. Johnson. 2011. Why can't we be friends?: Multicultural attitudes and friendships with international students. International Journal of Intercultural Relations 35: 41-48. [CrossRef] 
Yang, Fenggang. 1999. Chinese Christians in America: Conversion, Assimilation, and Adhesive Identities. Pennsylvania: Pennsylvania State University.

Yang, Fenggang. 2009. Religion in China under communism: A shortage economy explanation. Journal of Church and State 52: 3-33. [CrossRef]

Yang, Fenggang. 2018. 2018 Purdue Survey of Chinese Students and Scholars in the United States: A General Report. West Lafayette: Center on Religion and Chinese Society, Purdue University.

Yan, Kun. 2017. Chinese International Students' Stressors and Coping Strategies in the United States. Singapore: Springer.

Zhao, Chun-Mei, George D. Kuh, and Robert M. Carini. 2005. A comparison of international student and American student engagement in effective educational practices. The Journal of Higher Education 76: 209-31. [CrossRef]

(C) 2019 by the authors. Licensee MDPI, Basel, Switzerland. This article is an open access article distributed under the terms and conditions of the Creative Commons Attribution (CC BY) license (http://creativecommons.org/licenses/by/4.0/). 